\title{
Constrained Composite Differential Evolution Search for Optimal Site and Size of Distributed Generation Along with Reconfiguration in Radial Distribution Network
}

\author{
Aamir Ali ${ }^{1 a}$, Muhammad Usman Keerio ${ }^{1 b}$, Noor Hussain Mugheri ${ }^{1 c}$ \\ RECEIVED ON 02.05.2019, ACCEPTED ON 26.07.2019
}

\begin{abstract}
This paper proposed a novel method to find the Optimal Feeder Reconfiguration (OFR) of radial distribution network along with optimal site and size of Distributed Generation (DG) with an objective of power loss reduction. OFR and DG allocation problems are highly non-linear and complex optimization problems, complexity of problem is further increased with the addition of distribution operation constraints. In the last two decades, Evolutionary Algorithms (EAs) have been implemented successfully to find the OFR and DG allocation considering different objective functions. However, search space adopted by EAs are unconstrained, therefore numerous methodologies are adapted to discard infeasible solutions. The penalty approach is most widely used in the literature, it requires appropriate selection of penalty parameters using a tedious trial and error method. In this paper, a new EA Constrained Composite Differential Evolution $\left(C^{2} \mathrm{oDE}\right)$ is proposed find optimal capacity and site of DG along with reconfiguration problem. In the proposed algorithms three trial vectors are generated to strike balance among exploration and exploitation. Furthermore, to find the feasible solutions in the decision space two most widely used constraint handling techniques that include feasibility rule and $\varepsilon$-constrained method are added to select the trail vector and individuals respectively for the next generation. Proposed $C^{2}$ oDE method has been validated by considering IEEE 33-bus, 69-bus and 119-bus distribution networks at five different cases. Simulation results obtained shows better performance of proposed method against the most recent literature to find both OFR and DG allocation.
\end{abstract}

Keywords: Distributed generation, real power loss, constrained handling techniques, composite differential evolution, distribution network.

\section{INTRODUCTION}

I $\mathrm{n}$ the electrical power system, Distribution Network (DN) is the last portion to carries electric power from sub-transmission network to the utilization purpose and it is a very weak part of power system. Control and operation of $\mathrm{DN}$ are very complex, especially where the density of load is high and uncertain in nature and causes high active power loss and poor voltage regulation [1]. Furthermore, due to varying load and rapid growth of the distribution network, voltage stability has become a significant issue. Power loss in the DN will not be reduced for a fixed network configuration during uncertain load. Therefore, in the literature, many researchers have been made an effort to decrease power loss of distribution system. Optimal Feeder Reconfiguration (OFR) along with the best site and size of Distributed Generation (DG) placement are among those efforts made by researchers in order to overcome abovediscussed problems [2,3]. OFR is the process of interchanging the positions of tie and sectionalizing switches subject to respecting system constraints within their limit [4]. Furthermore, in DN load is

${ }^{1}$ Department of Electrical Engineering, Quaid-e-Awam University of Engineering, Science and Technology, Nawabshah, Sindh, Pakistan.

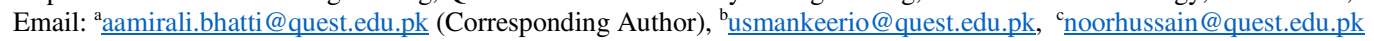

This is an open access article published by Mehran University of Engineering and Technology, Jamshoro under CC BY 4.0 International License. 
varying in nature and at the time when demand plus loss is greater than generation capacity, that makes to shut down additional demand and it is not economical. Therefore, to meet the additional load for the uninterruptable and reliable power supply DG units are added local power into the system [5]. Up to the present moment, appropriate site and size of DG and OFR are considered individually by many researchers in the literature.

In the literature first publication about the OFR considering branch and bound heuristic algorithm was presented by Merlin and Back [6]. The major drawback of this technique is that it is computationally not efficient, searches entire possible system configurations $2^{\text {n }}$, where $n$ illustrates the quantity of tie and sectionalizing switches. Shrimohammadi and Hong [7] recommended a heuristic technique built on branch and bound method subject to minimize power loss, main drawback of this algorithm is that during reconfiguration, simultaneous switching cannot be considered. Civanlar et al. [8] consider a very straightforward mathematical formula for the computation of active power loss due to switch exchange. Since the method is based on heuristic technique, evaluation of optimal solution in a systematic way is very difficult. Nara et al. in [9] proposed genetic algorithm (GA) for the OFR to decrease power loss. Furthermore, OFR of radial distribution system using metaheuristic techniques have been proposed recently in the literature with better results in order to find global minimum, that includes, cuckoo search algorithm (CSA) [10], modified tabu search (MTS) [11], Binary Group Search Optimization Algorithm (BGSOA) [12], Fireworks Algorithm (FWA) proposed in [13], Harmony Search Algorithm (HSA) [14], enhanced GA [15].

In many countries, internationally brings a new viewpoint that is deregulation of the electricity market for the DG, especially for the renewable type resources with a small capacity. The optimal range of DG units near the distribution system is typically between 0.2 MW to $10 \mathrm{MW}$ because of economic reasons $[16,17]$. In the past two decades number of researchers have made an effort to propose the new methods to find the solution of optimal DG allocation problem in order to minimize power loss. Celli et al. [18] suggested Multi-
Objective (MO) GA considering the $\varepsilon$-constraint method to find the feasible solutions of optimum DG capacity and site. Moreover, lot of research work is existed in the literature to find appropriate site and size of DG, that includes analytical approach [19], Genetic Algorithm (GA) [20], Bacterial Foraging Optimization (BFO) in [21], Artificial Neural Network (ANN) [22], Multi-Objective Particle Swarm Optimization (MOPSO) in [23]. Recently few numbers of studies have been accomplished to novelty simultaneously DG allocation and OFR, in which Adaptive CSA (ACSA) [24], Harmony Search Algorithm (HSA) [5], and Fireworks Algorithm (FWA) [25] are up-to-date few of the methods. This work proposed, a new optimization technique constrained composite differential evolution $\mathrm{C}^{2} \mathrm{oDE}$ [26] to find simultaneously OFR and DG allocation problem considering various constraints subject to reduce $I^{2} R$ losses and enhance voltage level. Furthermore, IEEE 33, 69 and 119-bus standard DNs are considered and compared with the recent methods to show the effectiveness of $\mathrm{C}^{2} \mathrm{oDE}$ algorithm. A summary of the contribution of this work listed as:

* Applying the new optimization method $\mathrm{C}^{2} \mathrm{oDE}$ to find the optimal DG allocation along with feeder reconfiguration.

- Feasibility rule and $\varepsilon$-constraint method are combined to select best trail vector and individual for the next population while optimizing objectives of real power loss minimization.

* Critical analysis of results especially against voltage, current, and DG capacity constraint violation in 33, 69, and 119-bus IEEE standard tests systems.

- Comparison of results with most recent studies on DG allocation and OFR with a similar experimental set-up.

Rest of the paper has been prepared as, in Section 2 formulation of problem is discussed, Section 3 provides the brief overview of constrained handling techniques and $\mathrm{C}^{2} \mathrm{oDE}$ algorithm, the simulation results and discussion are presented in Section 4 and outlines of the conclusion is presented in Section 5 . 


\section{PROBLEM FORMULATION}

\subsection{OBJECTIVE FUNCTION}

Simultaneously best site and capacity of DG allocation and Optimal Feeder Reconfiguration (OFR) has the main advantage to decrease power loss in the DN. The objective function (power loss) considering both for OFR and DG allocation, which is given by:

$$
\begin{aligned}
& \text { Minimize } \mathrm{f}=\left(\mathrm{P}_{\text {Loss }}^{\mathrm{R}}+\mathrm{P}_{\mathrm{Loss}}^{\mathrm{DG}}\right) \\
& \text { Subjected to } \mathrm{V}_{\min } \leq\left|\mathrm{V}_{\mathrm{i}}\right| \leq \mathrm{V}_{\max } \\
& \text { and }\left|\mathrm{I}_{\mathrm{i}, \mathrm{j}}\right| \leq \mid \mathrm{I}_{\mathrm{i}, \mathrm{j}} \max _{\mathrm{T}, \mathrm{DG}} \leq \mathrm{P}_{\mathrm{L}}+\mathrm{P}_{\text {Loss }}
\end{aligned}
$$

where, $\mathrm{P}_{\mathrm{Loss}}^{\mathrm{R}}$ and $\mathrm{P}_{\mathrm{Loss}}^{\mathrm{DG}}$ are the power loss after the OFR and DG allocation respectively. $V_{i}$ shows operating voltage at bus $i$ and $V_{\min }, V_{\max }$ are the minimum and maximum voltage constraints. $\mathrm{P}_{\mathrm{T}, \mathrm{DG}}$ shows total $\mathrm{DG}$ injection constraint in to the system, $\mathrm{P}_{\mathrm{L}}$ and $\mathrm{P}_{\mathrm{Loss}, \mathrm{i}}$ are total load and loss respectively in the circuit. So as to compute the objective function, it is first to run the power flow. Furthermore, power flow is done by using direct search-based algorithm [27]. After the power flow analysis, the power loss in a branch shown in Fig. 1 of DN between bus $i$ and $j$ can be calculated as:

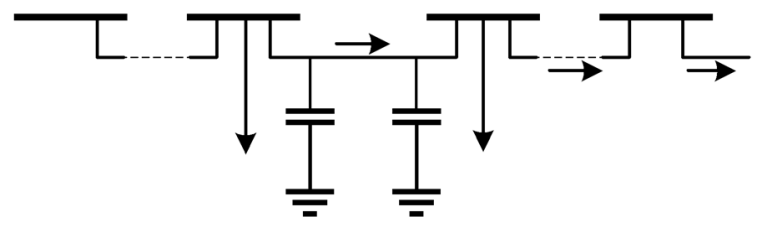

Fig. 1: One Line Diagram of Distribution System

$P_{\text {Loss }}(i, j)=R_{i j} \times \frac{\left(P_{i}^{2}+Q_{i}^{2}\right)}{\left|V_{i}\right|^{2}}$

Moreover, total amount of active power loss of the network, $\mathrm{P}_{\mathrm{T}, \mathrm{Loss}}$, can be computed in all the branches of the network, as follows:

$\mathrm{P}_{\mathrm{T}, \text { Loss }}=\sum_{\mathrm{i}=1}^{\mathrm{nl}} \mathrm{P}_{\mathrm{Loss}}(\mathrm{i}, \mathrm{j})$

where, $\mathrm{nl}$ is the total number of branches between their associated busses $\mathrm{i}$ and $\mathrm{j}$.

\section{* Minimization of active power loss using OFR}

OFR is a process to find the best status of tie and sectionalizing switches at which power loss is minimum subject to operating constraints are with their desirable limits. In the case of OFR, these constraints are maximum and minimum value of voltage profile, current carrying capacity of branch flow and DG capacity. The real power loss in a branch connected in between bus $i$ and $j$ after the OFR of distribution network can be given as:

$P_{\text {Loss }}^{R}(i, j)=R_{i j} \times \frac{\left(P_{i}^{R^{2}}+Q_{i}^{R^{2}}\right)}{\left|v_{i}^{R}\right|^{2}}$

where superscript $\mathrm{R}$ shows after optimal reconfiguration. However, total real power loss $\mathrm{P}_{\mathrm{T}, \mathrm{L} \text { Loss }}^{\mathrm{R}}$ in the feeder after reconfiguration may) then be computed by adding the losses of all branches, using:

$\mathrm{P}_{\mathrm{T}, \text { Loss }}^{\mathrm{R}}=\sum_{\mathrm{i}=1}^{\mathrm{nl}} \mathrm{P}_{\mathrm{Loss}}^{\mathrm{R}}(\mathrm{i}, \mathrm{j})$

Finally, the real power loss reduction $\triangle \mathrm{P}_{\text {Loss }}^{\mathrm{R}}$ using optimal reconfiguration is calculated by subtracting power loss before and after the reconfiguration, given as:

$\Delta \mathrm{P}_{\text {Loss }}^{\mathrm{R}}=\sum_{\mathrm{i}=1}^{\mathrm{nl}} \mathrm{P}_{\mathrm{T}, \text { Loss }}(\mathrm{i}, \mathrm{j})-\sum_{\mathrm{i}=1}^{\mathrm{nl}} \mathrm{P}_{\mathrm{T}, \text { Loss }}^{\mathrm{R}}(\mathrm{i}, \mathrm{j})$

\section{ACTIVE POWER LOSS REDUCTION USING DG ALLOCATION}

Computation of real power loss with the DG the arbitrary bus (say bus i) in the distribution network shown in Fig. 2, can be given as

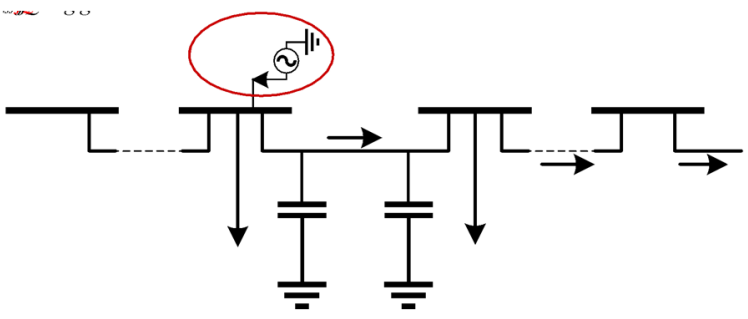

Fig. 2: Distribution Network with DG Installation at Bus i

$$
\begin{aligned}
P_{D G, L o s s}= & \frac{R_{i j}}{V_{i}^{2}}\left(P_{i}^{2}+Q_{i}^{2}\right)+\frac{R_{i j}}{V_{i}^{2}}\left(P_{D G}^{2}+Q_{D G}^{2}-\right. \\
& \left.2 P_{i} P_{D G}-2 Q_{i} Q_{D G}\right)
\end{aligned}
$$

In this paper, $\mathrm{Q}_{\mathrm{DG}}=0$, considering solar PV type DG, thus above equation can be rewritten as

$$
P_{D G, L o s s}=\frac{R_{i j}}{V_{i}^{2}}\left[\left(P_{i}-P_{D G}\right)^{2}+Q_{i}^{2}\right]
$$


whereas, net real power loss reduction $\Delta \mathrm{P}_{\mathrm{Loss}}^{\mathrm{DG}}$, is can be computed by subtracting equation (8) - (2), given as

$\triangle \mathrm{P}_{\mathrm{Loss}}^{\mathrm{DG}}=\frac{\mathrm{R}_{\mathrm{k}}}{\mathrm{V}_{\mathrm{k}}^{2}}\left(\mathrm{P}_{\mathrm{DG}}^{2}-2 \mathrm{P}_{\mathrm{i}} \mathrm{P}_{\mathrm{DG}}\right)$

\section{CONSTRAINT HANDLING TECHNIQUES AND OPTIMIZATION ALGORITHM}

\subsection{CONSTRAINED HANDLING TECHNIQUES (CHTs)}

The constrained are everywhere and all the engineering optimization problems are Constrained Optimization Problems (COP) and are generally along with objective function given as follows:

minimize $\mathrm{f}(\overrightarrow{\mathrm{x}}) ; \overrightarrow{\mathrm{x}}=\left(\mathrm{x}_{1}, \cdots, \mathrm{x}_{\mathrm{D}}\right) \in \mathrm{S}, \mathrm{L}_{\mathrm{i}} \leq \mathrm{x}_{\mathrm{i}} \leq \mathrm{U}_{\mathrm{i}}$

subject to: $g_{j}(\vec{x}) \leq 0,1, \ldots, l$

$$
h_{j}(\vec{x})=0, j=l+1, \ldots, m
$$

where $f(\vec{x})$ is objective function, $g_{j}(\vec{x})$ and $h_{j}(\vec{x})$ are the inequality and equality constraints respectively, $\vec{x}$ is decision vector, $\mathrm{D}$ is dimension numbers, $\mathrm{S}$ is decision space. The constraint violation on the $\mathrm{j}^{\text {th }}$ constraint $\mathrm{G}_{\mathrm{j}}(\overrightarrow{\mathrm{x}})$ can be calculated using Equation (10).

$$
\begin{aligned}
& \mathrm{G}_{\mathrm{j}}(\overrightarrow{\mathrm{x}})=\left\{\left(0, \mathrm{~g}_{\mathrm{j}}(\overrightarrow{\mathrm{x}}), \quad 1 \leq \mathrm{j} \leq l \quad\left(0, \mathrm{~h}_{\mathrm{j}}(\overrightarrow{\mathrm{x}})-\delta\right),\right.\right. \\
& l+1 \leq \mathrm{j} \leq \mathrm{m}
\end{aligned}
$$

where, $\delta$ is the tolerance value which is always positive, used to relax the equality constraints. Whereas the overall constraint violation given as:

$\mathrm{G}(\overrightarrow{\mathrm{X}})=\sum_{\mathrm{J}=1}^{\mathrm{m}} \mathrm{G}_{\mathrm{j}}(\overrightarrow{\mathrm{x}})$

The main goal of solving Constrained Optimization Problems (COP) to find the optimum in the feasible space. In the proposed optimization algorithm two types of CHTs are incorporated to increase the performances of the algorithm to find the feasible solutions, that includes feasibility rule (FR) and $\varepsilon$ Constrained Method (ECM). The FR is the famous constraint handling technique proposed by Deb in [28]. It compares two solutions (say $\overrightarrow{\mathrm{x}}_{\mathrm{i}}$ and $\overrightarrow{\mathrm{x}}_{\mathrm{j}}$ ) and following criteria is always imposed.

1. $\vec{x}_{i}$ is feasible and $\vec{x}_{j}$ is infeasible, $\vec{x}_{i}$ is preferred.
2. $\vec{x}_{i}$ and $\vec{x}_{j}$ both are infeasible and $G\left(\vec{x}_{i}\right)<G\left(\vec{x}_{j}\right), \vec{x}_{i}$ is preferred, the one with lesser degree of constraint violation.

3. $\vec{x}_{i}$ and $\vec{x}_{j}$ both are feasible, and $f\left(\vec{x}_{i}\right)<f\left(\vec{x}_{j}\right), \vec{x}_{i}$ is preferred, the one with lesser value of objective function.

The other technique is ECM proposed by Takahama and Sakai [29]. In this technique two individuals (say $\overrightarrow{\mathrm{x}}_{\mathrm{i}}$ and $\overrightarrow{\mathrm{x}}_{\mathrm{j}}$ ) are compared, and $\overrightarrow{\mathrm{x}}_{\mathrm{i}}$ is better than $\overrightarrow{\mathrm{x}}_{\mathrm{j}}$ if the following conditions are meet

$\left\{\mathrm{f}\left(\overrightarrow{\mathrm{x}}_{\mathrm{i}}\right)<\mathrm{f}\left(\overrightarrow{\mathrm{x}}_{\mathrm{j}}\right)\right.$

if $G\left(\vec{x}_{i}\right)<\varepsilon \wedge G\left(\vec{x}_{j}\right) \leq \varepsilon f\left(\vec{x}_{i}\right)<f\left(\vec{x}_{j}\right)$

if $\mathrm{G}\left(\vec{x}_{\mathrm{i}}\right)=\mathrm{G}\left(\overrightarrow{\mathrm{x}}_{\mathrm{j}}\right) \mathrm{G}\left(\overrightarrow{\mathrm{x}}_{\mathrm{i}}\right)<\mathrm{G}\left(\overrightarrow{\mathrm{x}}_{\mathrm{j}}\right)$, otherwise

In (13), $\varepsilon$ declines as the generation increases

$\varepsilon=\left\{\begin{array}{cc}\varepsilon_{0}\left(1-\frac{\mathrm{t}}{\mathrm{T}}\right)^{\mathrm{cp}} & \text { if } \frac{\mathrm{t}}{\mathrm{T}}<\mathrm{p} \\ 0 & \text { otherwise }\end{array}\right.$

$\mathrm{cp}=-\frac{\log \varepsilon_{0}+\lambda}{\log (1-\mathrm{p})}$

where $\varepsilon_{0}$ is the initial threshold, at the start of program its value is equal to maximum constraint violation, $t$ is current iteration and $\mathrm{T}$ is max iteration, $\lambda$ is equal to 6 suggested by [26] and p is constant control parameter which controls the convergence of objective function and is equal to 0.5 .

\section{CONSTRAINED COMPOSITE DIFFERENTIAL EVOLUTION $\left(C^{2}\right.$ oDE $)$}

All the practical optimization problems are formulated as COP. One of the most popular EA to solve COP is differential evolution (DE). Many DE variants have been used to solve engineering COP, as an excellent global optimizer, constrained composite $\mathrm{DE}\left(\mathrm{C}^{2} \mathrm{oDE}\right)$ [26] is proposed in this paper, that exhibits the few strength, that includes easy implementation, better searchability, combining the strengths of various trail vector generating strategies and self-adaption of various control parameters. The fundamental idea behind the proposed algorithm $\mathrm{C}^{2} \mathrm{oDE}$ is that it utilizes the three different trial vector generation strategies that make the tradeoff between convergence and diversity 
in order to get a global optimization solution. In addition, to incorporate different CHTs can be used to find the compromise between objective function and constraints. Basically, $\mathrm{C}^{2} \mathrm{oDE}$ consists of four steps, first an initial population $\vec{x}_{i}^{t}(i \in\{1 \ldots N P\})$ is randomly generated, second stage is called the mutation, in which mutation operator is used to produce the mutant vector $\vec{v}_{\mathrm{i}}^{\mathrm{t}}\left(\mathrm{i} \in\{1 \ldots \mathrm{NP}\}\right.$. In the proposed $\mathrm{C}^{2} \mathrm{oDE}$ algorithm three mutation operators have been used, that includes

1) DE/current-to-rand/l

$\overrightarrow{\mathrm{v}}_{\mathrm{i}}^{\mathrm{t}}=\overrightarrow{\mathrm{x}}_{\mathrm{i}}^{\mathrm{t}}+\mathrm{F} \cdot\left(\overrightarrow{\mathrm{x}}_{\mathrm{r} 1}^{\mathrm{t}}-\overrightarrow{\mathrm{x}}_{\mathrm{i}}^{\mathrm{t}}\right)+\mathrm{F} \cdot\left(\overrightarrow{\mathrm{x}}_{\mathrm{r} 2}^{\mathrm{t}}-\overrightarrow{\mathrm{x}}_{\mathrm{r} 3}^{\mathrm{t}}\right)$

2) Modified DE/current-to-best/l

$\vec{v}_{i}^{t}=\vec{x}_{i}^{t}+F \cdot\left(\vec{x}_{\text {best }}^{\mathrm{t}}-\overrightarrow{\mathrm{x}}_{\mathrm{r} 1}^{\mathrm{t}}\right)+\mathrm{F} \cdot\left(\overrightarrow{\mathrm{x}}_{\mathrm{r} 2}^{\mathrm{t}}-\overrightarrow{\mathrm{x}}_{\mathrm{r} 3}^{\mathrm{t}}\right)$

3) DE/rand-to-best/l

$\overrightarrow{\mathrm{v}}_{\mathrm{i}}^{\mathrm{t}}=\overrightarrow{\mathrm{x}}_{\mathrm{r} 1}^{\mathrm{t}}+\mathrm{F} \cdot\left(\overrightarrow{\mathrm{x}}_{\text {best }}^{\mathrm{t}}-\overrightarrow{\mathrm{x}}_{\mathrm{r} 1}^{\mathrm{t}}\right)+\mathrm{F} \cdot\left(\overrightarrow{\mathrm{x}}_{\mathrm{r} 2}^{\mathrm{t}}-\overrightarrow{\mathrm{x}}_{\mathrm{r} 3}^{\mathrm{t}}\right)$

where, $\overrightarrow{\mathrm{x}}_{\mathrm{r} 1}^{\mathrm{t}}$ to $\overrightarrow{\mathrm{x}}_{\mathrm{r} 5}^{\mathrm{t}}$ are the randomly selected distinct individuals form the population 1 to NP, $\vec{x}_{\text {best }}^{t}$ is the best decision vector. Third stage is called crossover, in which crossover operator is used pairwise between mutation vector $\vec{v}_{i}^{t}$ and its associated target vector $\vec{x}_{i}^{t}$ to yield trial vector $\vec{u}_{i}^{t}$. Commonly binomial crossover is used in this stage

$u_{i, j}^{t}= \begin{cases}v_{t i j}^{t}, & \text { if rand } d_{j}<C R \text { or } j=j_{\text {rand }} \\ x_{i j}^{t}, & \text { otherwise }\end{cases}$

where, $x_{i, j}^{t}, u_{i, j}^{t}$ and $v_{i, j}^{t}$ are the $j^{\text {th }}$ dimension of $\vec{x}_{i}^{t}, \vec{u}_{i}^{t}$ and $\vec{v}_{i}^{t}$ respectively, CR is randomly selected value from parameter pool, $\mathrm{J}_{\mathrm{rand}}$ is the random integer produced between 1 to $\mathrm{D}$. At the end selection operator is achieved between $\vec{x}_{i}^{t}$ and $\vec{u}_{i}^{t}$ and the better one is the new candidate for the next generation.

$\overrightarrow{\mathrm{x}}_{\mathrm{i}}^{\mathrm{t}+1}= \begin{cases}\overrightarrow{\mathrm{u}}_{\mathrm{i}}^{\mathrm{t}}, & \text { if } \mathrm{f}\left(\overrightarrow{\mathrm{u}}_{\mathrm{i}}^{\mathrm{t}}\right)<\mathrm{f}\left(\overrightarrow{\mathrm{x}}_{\mathrm{i}}^{\mathrm{t}}\right) \\ \overrightarrow{\mathrm{x}}_{\mathrm{i}}^{\mathrm{t}}, & \text { otherwise }\end{cases}$

The Framework of proposed $\mathrm{C}^{2} \mathrm{oDE}$ algorithm is shown in Fig. 3.

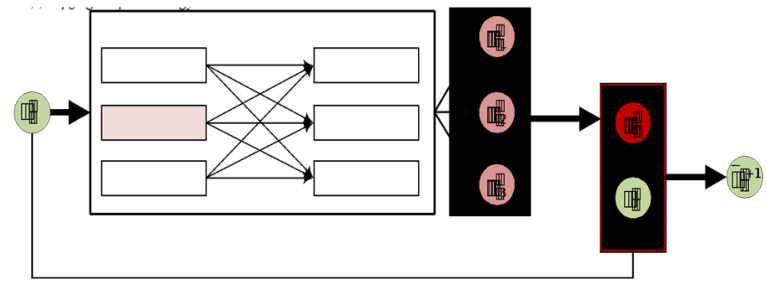

Fig. 3: Framework of $C^{2} \mathrm{ODE}$ Algorithm
It is clear from the Fig.3 that, there are three offsprings will be generated for each target vector. In the proposed algorithm two parameter pools were established $\mathrm{F}_{\text {pool }}$ and $\mathrm{CR}_{\text {pool }}$ called scaling factor and cross over respectively. When EAs are applying to find the solution of COPs, in order to find the outstanding performance, it deserves much attention into two issues. First the compromise made between exploration and exploitation, whereas, second is the compromise between objective function and constraints. As said by No Free Lunch (NFL) theorem [30], to apply two different CHTs rather than one in the different phases. Thus, in the proposed $\mathrm{C}^{2} \mathrm{ODE}$ algorithm two different CHTs at the stage of preselection and selection are introduced in order to suit its characteristics. Optimal reconfiguration along with DG allocation problems are complicated in nature; therefore, a restart scheme is used to get-out from trapped into local optima. Restart scheme is triggered if standard deviation of objective function and constraint violation is less than the pre specified threshold value. The detailed flowchart of $\mathrm{C}^{2} \mathrm{ODE}$ is given in Fig. 4 and the pseudocode is given in Table 1.

Table 1: Pseudocode of Proposed $C^{2} \mathrm{ODE}$ Algorithm

Proposed $\mathrm{C}^{2} \mathrm{oDE}$ Algorithm

Input

D; /*set the number of decision variable*/

$\mathrm{x}_{\mathrm{i}}^{\mathrm{L}}$ and $\mathrm{x}_{\mathrm{i}}^{\mathrm{U}}$; /*set the lower and upper

bound of decision variables*/

$\mathrm{N}_{\mathrm{P}}$; /*Set population size*/

MAX $X_{\text {Feval }} / *$ set the maximum function

evolution (stopping criteria) */

Initialization

$t=1 ; / *$ Set the generation number*/

$\overrightarrow{\mathrm{x}}_{\mathrm{i}}^{\mathrm{t}}(\mathrm{i} \in\{1 \ldots \mathrm{NP}\}) ; / *$ Randomly generate

initial population between lower (L) and upper (U) bounds*/

$\mathrm{F}_{\text {pool }}$; $\mathrm{CR}_{\text {pool }}$; /*Set $\mathrm{C}^{2} \mathrm{oDE}$ parameters, pool of mutation factor $(\mathrm{F})$ and cross over rate

$(\mathrm{CR}) * 1$

Evaluation

1. Evaluate objective function and overall constraint violation using eq. (10) and (12) of $\overrightarrow{\mathrm{x}}_{\mathrm{i}}^{\mathrm{t}}$;

2. $\mathrm{FEs}=\mathrm{N}_{\mathrm{p}} ; / *$ FEs shows the number function evaluation*/

3. Tune the $\varepsilon$ value of ECM using eq. (14);

4. $\overrightarrow{\mathrm{x}}_{\mathrm{i}}^{\mathrm{t}+1}=\varnothing ;$; $*$ pre allocate the population for the next generation*/

Main Loop 
5. for $i=1$ : Np do

6. Generate three mutation vectors $\vec{v}_{\mathrm{i} 1}^{\mathrm{t}}, \mathrm{v}_{\mathrm{i} 2}^{\mathrm{t}}$ and $\overrightarrow{\mathrm{v}}_{\mathrm{i} 3}^{\mathrm{t}}$ using eq. (16) to (17);

7. Generate three offspring $\vec{u}_{i 1}^{t}, \vec{u}_{i 2}^{t}$ and $\vec{u}_{i 3}^{t}$ such as $\overrightarrow{\mathrm{u}}_{\mathrm{i} 1}^{\mathrm{t}}=\overrightarrow{\mathrm{v}}_{\mathrm{i} 1}^{\mathrm{t}}$, however $\overrightarrow{\mathrm{u}}_{\mathrm{i} 2}^{\mathrm{t}}$ and $\overrightarrow{\mathrm{u}}_{\mathrm{i} 3}^{\mathrm{t}}$ are generated by using binomial crossover using eq. (19);

8. Evaluate the objective function and constraint violation using $\overrightarrow{\mathrm{u}}_{\mathrm{i} 1}^{\mathrm{t}}, \overrightarrow{\mathrm{u}}_{\mathrm{i} 2}^{\mathrm{t}}$ and $\overrightarrow{\mathrm{u}}_{\mathrm{i} 3}^{\mathrm{t}}$;

9. Select trial vector $\overrightarrow{\mathrm{u}}_{\mathrm{i}}^{\mathrm{t}}$ for $\overrightarrow{\mathrm{x}}_{\mathrm{i}}^{\mathrm{t}}$ from $\overrightarrow{\mathrm{u}}_{\mathrm{i} 1}^{\mathrm{t}}, \overrightarrow{\mathrm{u}}_{\mathrm{i} 2}^{\mathrm{t}}$ and $\overrightarrow{\mathrm{u}}_{\mathrm{i} 3}^{\mathrm{t}}$ by applying feasibility rule;
10. Compare $\vec{u}_{i}^{t}$ and $\vec{x}_{i}^{t}$ by using ECM, and put better one for the next population $\overrightarrow{\mathrm{x}}_{\mathrm{i}}^{\mathrm{t}+1}$;

11. $\mathrm{FEs}=\mathrm{FEs}+3$;

12. end /*for loop end $* /$;

13. Implement the restart scheme;

14. $\mathrm{t}=\mathrm{t}+1$;

15. if FEs $\geq$ MAX $_{\mathrm{Feval}}$, then save the results Otherwise go to step 3.

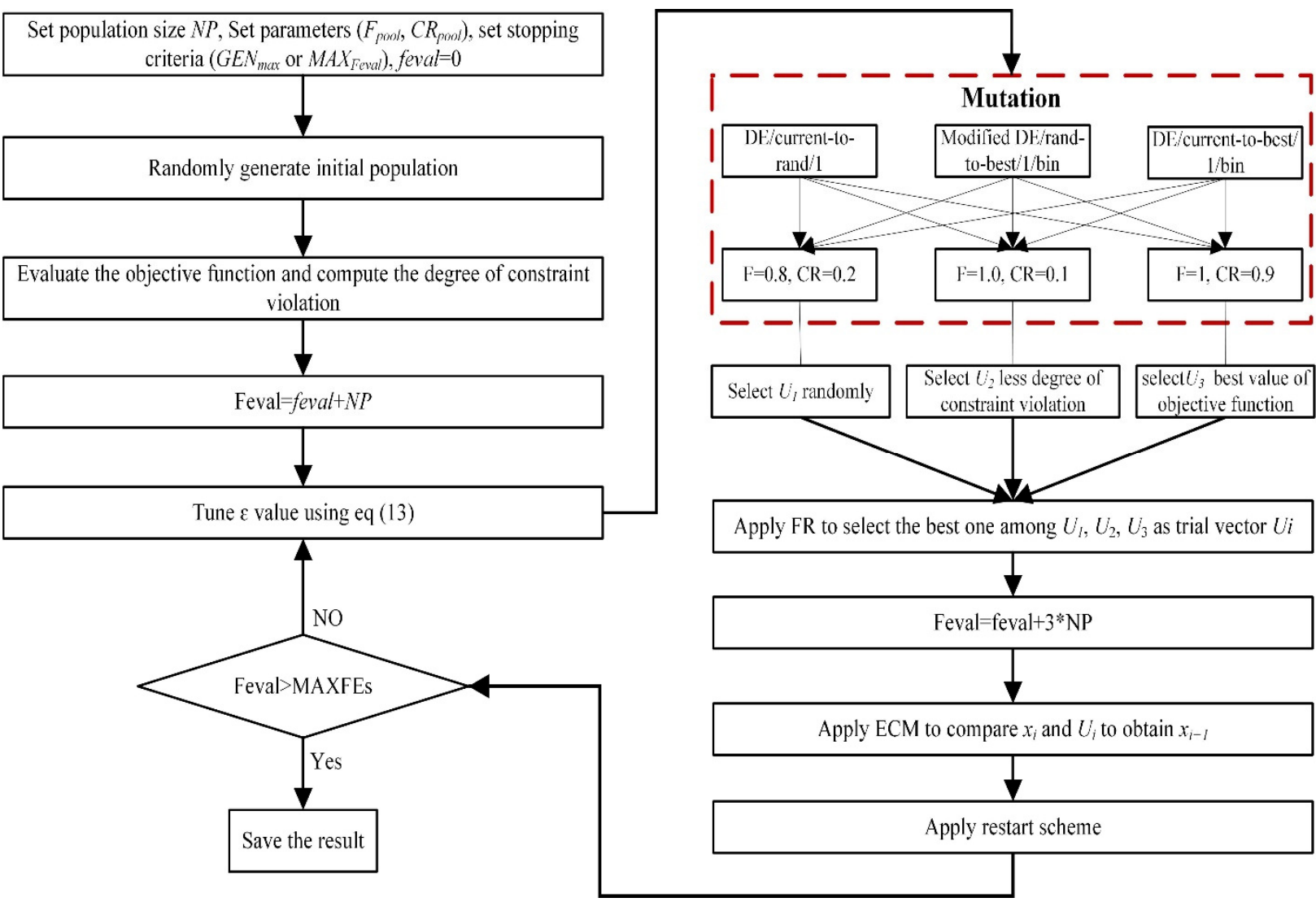

Fig. 4: Flowchart for the implementation of $\mathrm{C}^{2} \mathrm{ODE}$

\section{SIMULATION RESULTS AND DISCUSSION}

In this section, the optimization method $\mathrm{C}^{2} \mathrm{oDE}$ is applied to solve the OFR along with appropriate placement and capacity of DG allocation problem, in order to examine its applicability. In addition, $\mathrm{C}^{2} \mathrm{oDE}$ is applied to three standard IEEE radial distribution systems from small to large scale that includes, 33, 69 and 119-bus. Furthermore, five different cases are considered for the simulation of the distribution network, that are:

Case 1: Only OFR.

Case 2: Only optimal site and size of DG allocation.

Case 3: DG allocation after the OFR.

Case 4: OFR after the DG allocation.

Case 5: Simultaneous OFR and DG allocation.

Maximum number of DG installation in all the cases is limited to three and the parameters of proposed 
$\mathrm{C}^{2} \mathrm{oDE}$ algorithm for the simulation of standard IEEE test systems are shown in Table 2.

Table 2: Parameters of $C^{2}$ ODE Algorithm for The IEEE Test Systems

\begin{tabular}{|c|c|c|}
\hline $\begin{array}{c}\text { Test } \\
\text { system }\end{array}$ & Parameter & Values \\
\hline \multirow{6}{*}{$\begin{array}{l}33 \text { and } \\
69-\text { bus }\end{array}$} & DG value & 0.2 to 2 (MW) \\
\hline & $\mathrm{N}_{\mathrm{p}}$ & 100 \\
\hline & MAX $_{\text {Feval }}$ & 30000 \\
\hline & $\begin{array}{l}\text { Max iteration }(\mathrm{T})= \\
\mathrm{MAX}_{\mathrm{Feval}} / 3 \times \mathrm{N}_{\mathrm{P}}\end{array}$ & 100 \\
\hline & Mutation Factor $(\mathrm{F})$ & {$[0.8,1.0,1.0]$} \\
\hline & Crossover rate (CR) & {$[0.2,0.1,0.9]$} \\
\hline \multirow[t]{6}{*}{ 119-bus } & DG value & 0.2 to $5 \mathrm{MW}$ \\
\hline & $\mathrm{N}_{\mathrm{p}}$ & 50 \\
\hline & MAX $_{\text {Feval }}$ & 120000 \\
\hline & $\begin{array}{c}\text { Max iteration }(\mathrm{T})= \\
\mathrm{MAX}_{\mathrm{Feval}} / 3 \times \mathrm{N}_{\mathrm{P}}\end{array}$ & 800 \\
\hline & Mutation Factor $(\mathrm{F})$ & {$[0.8,1.0,1.0]$} \\
\hline & Crossover rate (CR) & {$[0.2,0.1,0.9]$} \\
\hline
\end{tabular}

\section{IEEE 33-BUS SYSTEM}

The small scale 33-bus network comprises of 37 branches out of which 32 branches involve sectionalizing and 5 branches include tie switches. The load and the line data for this system is taken from MTAPOWER [31], total demand of this network is $3.72 \mathrm{MW}+j 2.3 \mathrm{MVAr}$ respectively. The one-line diagram of 33-bus network is as shown in Fig. 5, whereas, Table 3 shows the fundamental loops of this network.

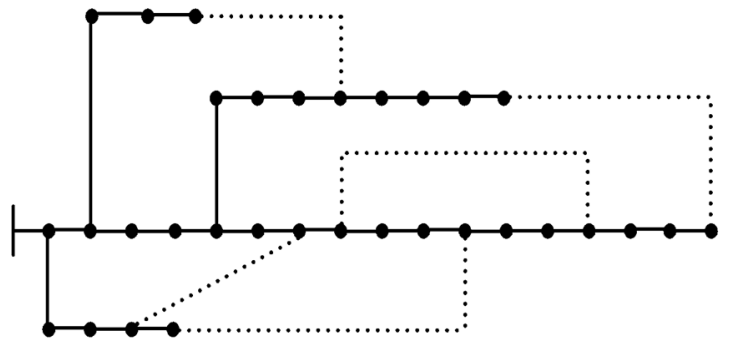

Fig. 5: One-Line Line Diagram of IEEE 33-Bus Test System

Table 3: Loops of 33-Bus Test System

\begin{tabular}{|c|c|}
\hline Loop & Branches \\
\hline $\mathrm{FL}_{1}$ & $8,9,10,11,21,33,35$ \\
\hline $\mathrm{FL}_{2}$ & $2,3,4,5,6,7,18,19,20,33$ \\
\hline $\mathrm{FL}_{3}$ & $12,13,14,34$ \\
\hline $\mathrm{FL}_{4}$ & $15,16,17,29,30,31,32,36$ \\
\hline $\mathrm{FL}_{5}$ & $22,23,24,25,26,27,28,37$ \\
\hline
\end{tabular}

The simulation results of all cases of $\mathrm{C}^{2} \mathrm{oDE}$ algorithm is shown in the third column of Table 4.

It is clearly noticed from the Table 4 that, in base case power loss is $202.68 \mathrm{~kW}$, which is reduced to 139.551 $\mathrm{kW}$ that is about 30.93 percentage reduction, while in case 2 to case 5 that reduced up to $71.454442,58.87$, 57.569689, 52.720480, which are about 64.74, 70.95, 71.60 and 73.988 percentage active power loss reduction respectively. Table 4 also shows the magnitude of minimum bus voltage which is enhanced remarkably in all the cases in comparison to base case. Fig. 6 shows the comparison of voltage profile for all the cases of 33-bus system.

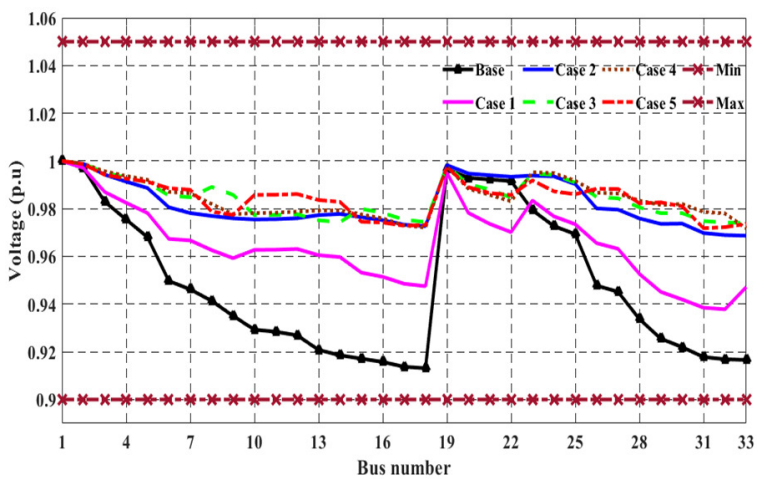

Fig. 6: Voltage Profile of All Cases for 33-Bus System

It can be noticed from Fig. 6, that profile of voltage is enhanced significantly in all the cases in comparison to the base case after using OFR and DG allocation. In addition, distribution of current in all the branches are well uniform in all cases especially in case 5 , and also the current in each branch is less than the maximum desirable limit, shown in Fig. 7.

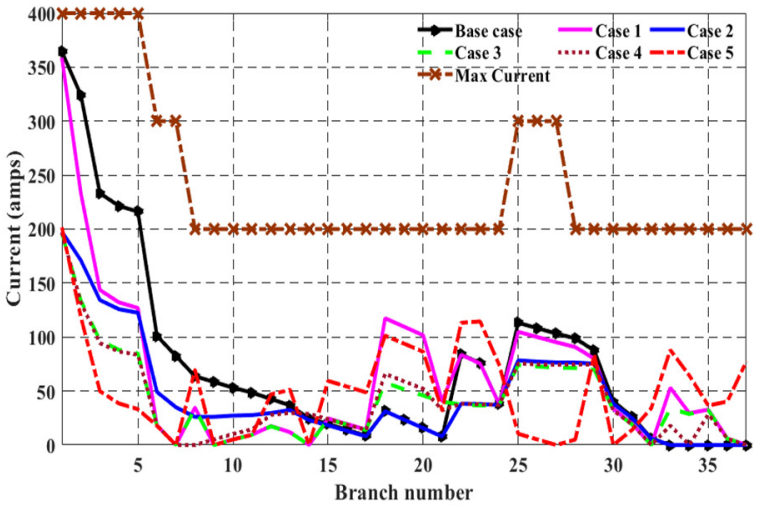

Fig. 7: Current Distribution of All Cases for IEEE 33-Bus System 

Reconfiguration in Radial Distribution Network

Table 4: Simulation Results of IEEE 33-Bus Distribution System

\begin{tabular}{|c|c|c|c|c|c|}
\hline $\begin{array}{l}\text { Case \# } \\
\text { (description) }\end{array}$ & Item & $\mathrm{C}^{2} \mathrm{oDE}$ & ACSA [24] & FWA $[25]$ & HSA [5] \\
\hline Base Case & \multicolumn{5}{|c|}{ Tie switch branches $=33,34,35,36,37 ; P_{\text {Loss }}(\mathrm{kW})=202.68 ;$ bus voltage $\mathrm{Min}(\mathrm{p} . \mathrm{u})=0.9108$} \\
\hline \multirow{4}{*}{$\begin{array}{c}\text { Case } 1 \\
\text { (reconfiguration } \\
\text { only) }\end{array}$} & Tie switch branches & $9,7,14,32,37$ & $7,14,9,32,28$ & $7,14,9,32,28$ & $7,14,9,32,28$ \\
\hline & $\mathrm{P}_{\text {Loss }}(\mathrm{kW})$ & 139.551 & 139.98 & 139.98 & 138.06 \\
\hline & $\%$ Loss reduction & 31.147 & 30.93 & 30.93 & 31.88 \\
\hline & bus voltage Min: (p.u) & 0.93782 & 0.9143 & 0.9143 & 0.9342 \\
\hline \multirow{5}{*}{$\begin{array}{c}\text { Case } 2 \text { (DG } \\
\text { allocation only) }\end{array}$} & Tie switch branches & $33,34,35,36,37$ & $33,34,35,36,37$ & $33,34,35,36,37$ & $33,34,35,36,37$ \\
\hline & $\begin{array}{l}\text { Size of DG in MW } \\
\text { (Bus Number) }\end{array}$ & $\begin{array}{l}1.0713(30) \\
0.7540(14) \\
1.0994(24)\end{array}$ & $\begin{array}{l}0.7798(14), 1.1251 \\
(24), 1.3496(30)\end{array}$ & $\begin{array}{l}0.5897(14), \\
0.1895(18), \\
1.0146(32)\end{array}$ & $\begin{array}{l}0.1070(18), \\
0.5724(17), \\
1.0462(33)\end{array}$ \\
\hline & Power loss $(\mathrm{kW})$ & 71.454442 & 74.26 & 88.68 & 96.76 \\
\hline & \% Loss reduction & 64.74 & 63.26 & 56.24 & 52.26 \\
\hline & bus voltage Min: (p.u) & 0.9686553 & 0.9778 & 0.9680 & 0.9670 \\
\hline \multirow{5}{*}{$\begin{array}{c}\text { Case } 3 \text { (DG } \\
\text { allocation after } \\
\text { optimal } \\
\text { reconfiguration) }\end{array}$} & Tie switch branches & $9,7,14,32,37$ & $7,14,9,32,28$ & $7,14,9,32,28$ & $7,14,9,32,28$ \\
\hline & $\begin{array}{l}\text { Size of DG in MW } \\
\text { (Bus Number) }\end{array}$ & $\begin{array}{l}0.9316(8), \\
1.0681(24), \\
0.9503(30)\end{array}$ & $\begin{array}{l}1.7536(29), 0.5397 \\
(12), 0.5045(16)\end{array}$ & $\begin{array}{l}0.5996(32), \\
0.3141(33) \\
0.1591(18)\end{array}$ & $\begin{array}{l}0.2686(32), \\
0.1611(31) \\
0.6612(30)\end{array}$ \\
\hline & Power loss $(\mathrm{kW})$ & 58.87 & 58.79 & 83.91 & 97.13 \\
\hline & $\%$ Loss reduction & 70.95 & 71.00 & 58.59 & 52.07 \\
\hline & bus voltage Min: (p.u) & 0.97406 & 0.9802 & 0.9612 & 0.9479 \\
\hline \multirow{5}{*}{$\begin{array}{c}\text { Case } 4 \text { (optimal } \\
\text { reconfiguration } \\
\text { after DG } \\
\text { installation) }\end{array}$} & Tie switch branches & $8,7,34,32,37$ & $33,9,8,36,27$ & $7,34,9,32,28$ & - \\
\hline & $\begin{array}{l}\text { Size of DG in MW } \\
\text { (Bus Number) }\end{array}$ & $\begin{array}{l}1.0713(30) \\
0.7540(14) \\
1.0994(24)\end{array}$ & $\begin{array}{l}0.7798(14), \\
1.1251(24), \\
1.3496(30)\end{array}$ & $\begin{array}{l}0.5897(14), \\
0.1895(18), \\
1.0146(32)\end{array}$ & - \\
\hline & Power loss $(\mathrm{kW})$ & 57.569 & 62.98 & 68.28 & - \\
\hline & \% Loss reduction & 71.60 & 68.93 & 66.31 & - \\
\hline & bus voltage Min: (p.u) & 0.9717 & 0.9826 & 0.9712 & - \\
\hline \multirow{5}{*}{$\begin{array}{c}\text { Case } 5 \\
\text { (Simultaneous } \\
\text { optimal } \\
\text { reconfiguration } \\
\text { and DG } \\
\text { installation) }\end{array}$} & Tie switch branches & $9,7,14,30,27$ & $33,34,11,31,28$ & - & - \\
\hline & $\begin{array}{l}\text { Size of DG in MW } \\
\text { (Bus Number) }\end{array}$ & $\begin{array}{l}0.7744(33) \\
1.2907(25) \\
0.5792(12)\end{array}$ & $\begin{array}{l}0.8968(18), 1.4381 \\
(25), 0.9646(7)\end{array}$ & & - \\
\hline & Power loss $(\mathrm{kW})$ & 52.720 & 53.21 & - & - \\
\hline & $\%$ Loss reduction & 73.988 & 73.75 & - & - \\
\hline & bus voltage Min: (p.u) & 0.9717 & 0.9806 & - & - \\
\hline
\end{tabular}

Fig. 7 clearly shows that; the current is more uniformly distributed in all the branches of case 5 compared to all other cases. Highest power loss reduction has also appeared in case 5 as shown in Table 4, in which simultaneous OFR and DG site and size problem is optimized. Furthermore, all the simulation results of proposed $\mathrm{C}^{2} \mathrm{oDE}$ algorithm are compared with the methods ACSA [24], FWA [25] and HSA [5] available in the literature to show its effectiveness and superiority and are presented in Table 4. It is clearly observed from the Table 4, that in most of the cases in comparison to a minimization of real power losses, proposed $\mathrm{C}^{2} \mathrm{oDE}$ algorithm is better than the ACSA [24], FWA [25] and HSA [5]. The convergence results of 33-bus system for all cases is shown in Fig. 8. It is clear from Fig. 8, that objective function in case 5 is minimum compared to all other cases.

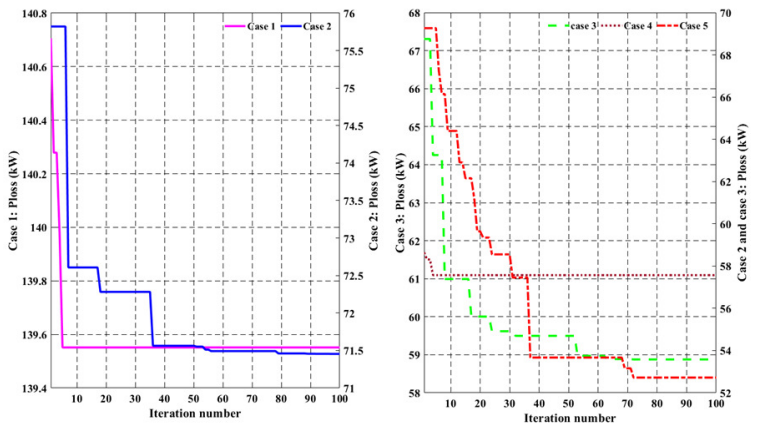

Fig. 8: Convergence Curve of Case 1 to Case 5 for IEEE 33Bus

\section{IEEE 69-BUS SYSTEM}

The medium scale 69-bus network comprises of 73 branches out of which 68 branches connected with normally closed switches called sectionalizing switches and remaining 5 branches involve tie 
switches (normally open). Load and branch data for a 69-bus network are taken from MTAPOWER [31], total active and reactive power demands of this network are 3.802 MW and 2.696 MVAr. The typical one-line diagram of 69-bus distribution system is as shown in Fig. 9, whereas, Table 5 shows the fundamental loops of this network.

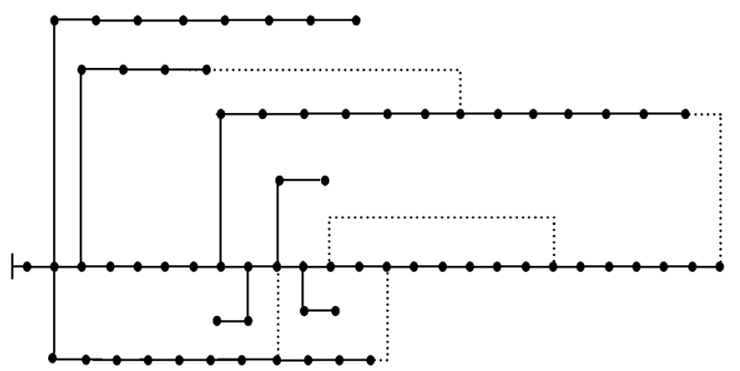

Fig. 9: One-Line Diagram of IEEE 69-Bus Radial Network

In the normal operating condition, switches in the branches 69, 70, 71, 72 and 73 are unlocked. Similar to IEEE 33-bus system loops of 69-bus system are obtained and are shown in Table 5.

Table 5: Loops of 69-Bus Test System

\begin{tabular}{|c|c|}
\hline Loop & \multicolumn{1}{|c|}{ Branches } \\
\hline $\mathrm{FL}_{1}$ & $3,4,5,6,7,8,9,10,35,36,37,38,39,40,41,42,69$ \\
\hline $\mathrm{FL}_{2}$ & $46,47,48,49,52,53,54,55,56,57,58,72$ \\
\hline $\mathrm{FL}_{3}$ & $11,12,13,14,43,44,45,71$ \\
\hline $\mathrm{FL}_{4}$ & $15,16,17,18,19,20,70$ \\
\hline $\mathrm{FL}_{5}$ & $21,22,23,24,25,26,59,60,61,62,63,64,73$ \\
\hline
\end{tabular}

69-bus system is also simulated for five cases and the simulation results are shown in Table 6.

It is clearly noticed from the Table 6 , without OFR and DG allocation power loss in the 69-bus network is $224.89 \mathrm{~kW}$, that is decreased to $98.6056,69.428463$, $35.1621,39.17711$ and 35.1621 in case 1, 2, 3, 4 and 5 respectively. Percentage reduction in active loss in case 1 to case 5 is $56.15,69.12,84.36,82.579$ and 84.36 respectively. In comparison to all other methods shown in Table 6 , reduction in power loss using $\mathrm{C}^{2} \mathrm{ODE}$, is highest, in case 2, 3 and 5, which shows the

Table 6: Simulation Results of IEEE 69-Bus Test System

\begin{tabular}{|c|c|c|c|c|c|}
\hline $\begin{array}{c}\text { Case \# } \\
\text { (Description) }\end{array}$ & Item & Proposed $C^{2}$ oDE & ACSA [24] & FWA [25] & HSA [5] \\
\hline Base Case & \multicolumn{5}{|c|}{ Tie switch branches $=69,70,71,72,73 ; P_{\text {Loss }}(\mathrm{kW})=224.89 ;$ bus voltage $\operatorname{Min}:(\mathrm{p} . \mathrm{u})=0.9092$} \\
\hline \multirow{4}{*}{$\begin{array}{c}\text { Case } 1 \\
\text { (reconfiguration } \\
\text { only) }\end{array}$} & Tie switch branches & $69,57,14,70,61$ & $69,70,14,57,61$ & $69,70,14,56,61$ & $69,18,13,56,61$ \\
\hline & $\mathrm{P}_{\text {Loss }}(\mathrm{kW})$ & 98.60 & 98.59 & 98.59 & 99.35 \\
\hline & $\%$ Loss reduction & 56.15 & 56.16 & 56.16 & 55.85 \\
\hline & bus voltage Min: (p.u) & 0.9495 & 0.9495 & 0.9495 & 0.9428 \\
\hline \multirow{5}{*}{$\begin{array}{c}\text { Case } 2 \text { (DG } \\
\text { allocation only) }\end{array}$} & Tie switch branches & $69,70,71,72,73$ & $69,70,71,72,73$ & $69,70,71,72,73$ & \\
\hline & $\begin{array}{l}\text { Size of DG in MW } \\
\text { (Bus Number) }\end{array}$ & $\begin{array}{l}0.3803(18), \\
1.7189(61), \\
0.5268(11),\end{array}$ & $\begin{array}{l}0.6022(11) \\
0.3804(18) \\
2(61)\end{array}$ & $\begin{array}{l}0.4085(65) \\
1.1986(61) \\
0.2258(27)\end{array}$ & $\begin{array}{l}0.1018(65) \\
0.3690(64) \\
1.3024(63)\end{array}$ \\
\hline & $\mathrm{P}_{\text {Loss }}(\mathrm{kW})$ & 69.428463 & 72.44 & 77.85 & 86.77 \\
\hline & \% Loss reduction & 69.12 & 67.79 & 65.39 & 61.43 \\
\hline & bus voltage Min: (p.u) & 0.97897 & 0.9890 & 0.9740 & 0.9677 \\
\hline \multirow{5}{*}{$\begin{array}{c}\text { Case } 3 \text { (DG } \\
\text { allocation after } \\
\text { optimal } \\
\text { reconfiguration) }\end{array}$} & Tie switch branches & $69,57,14,70,61$ & $69,70,14,57,61$ & $69,70,14,56,61$ & $69,18,13,56,61$ \\
\hline & $\begin{array}{l}\text { Size of DG in MW } \\
\text { (Bus Number) }\end{array}$ & $\begin{array}{l}0.53755(11), \\
0.49035(64), \\
1.4339(61) .\end{array}$ & $\begin{array}{l}1.7254(61) \\
0.4666(64) \\
0.3686(12)\end{array}$ & $\begin{array}{l}1.0014(61) \\
0.2145(62) \\
0.1425(64)\end{array}$ & $\begin{array}{l}1.0666(61) \\
0.3525(60) \\
0.4257(58)\end{array}$ \\
\hline & $\mathrm{P}_{\text {Loss }}(\mathrm{kW})$ & 35.1621 & 37.23 & 43.88 & 51.3 \\
\hline & \% Loss reduction & 84.36 & 83.45 & 80.49 & 77.2 \\
\hline & bus voltage Min: (p.u) & 0.9813 & 0.9870 & 0.9720 & 0.9619 \\
\hline \multirow{5}{*}{$\begin{array}{c}\text { Case } 4 \text { (optimal } \\
\text { reconfiguration } \\
\text { after DG } \\
\text { installation) }\end{array}$} & Tie switch branches & $69,58,13,70,64$ & $69,70,14,58,64$ & $69,70,12,58,61$ & - \\
\hline & $\begin{array}{l}\text { Size of DG in MW (Bus } \\
\text { Number) }\end{array}$ & $\begin{array}{l}0.380353(18), \\
1.718961(61), \\
0.526822(11)\end{array}$ & $\begin{array}{l}0.6022(11) \\
0.3804(18) \\
2(61)\end{array}$ & $\begin{array}{l}0.4085(65) \\
1.1986(61) \\
0.2258(27)\end{array}$ & - \\
\hline & $\mathrm{P}_{\text {Loss }}(\mathrm{kW})$ & 39.17711 & 41.13 & 39.69 & - \\
\hline & \% Loss reduction & 82.579 & 81.71 & 82.35 & - \\
\hline & bus voltage Min: (p.u) & 0.976865 & 0.9828 & 0.9763 & - \\
\hline \multirow{5}{*}{$\begin{array}{c}\text { Case } 5 \\
\text { (Simultaneous } \\
\text { optimal } \\
\text { reconfiguration } \\
\text { and DG } \\
\text { installation) }\end{array}$} & Switches & $69,57,14,70,61$ & $69,70,14,58,61$ & & \\
\hline & $\begin{array}{l}\text { Size of DG in MW } \\
\text { (Bus Number) }\end{array}$ & $\begin{array}{l}0.53753(11), \\
0.49035(64), \\
1.43399(61) .\end{array}$ & $\begin{array}{l}0.5413(11) \\
0.5536(65) \\
1.7240(61) \\
\end{array}$ & & \\
\hline & $\mathrm{P}_{\text {Loss }}(\mathrm{kW})$ & 35.1621 & 37.02 & - & - \\
\hline & \% Loss reduction & 84.36 & 83.54 & - & - \\
\hline & bus voltage Min: (p.u) & 0.9813338 & 0.9869 & - & - \\
\hline
\end{tabular}


effectiveness of $\mathrm{C}^{2} \mathrm{oDE}$ algorithm compared to ACSA [24], FWA [25] and HSA [5] methods. It can clearly demonstrate from Table 6 that case 5 in which simultaneous DG injection along with optimal reconfiguration are more effective compared to all other cases. However voltage profile is slightly less in case 2 to case 5 as compared to ACSA [24], that is because of more DG power injected by ACSA compared to proposed $\mathrm{C}^{2} \mathrm{oDE}$. Fig. 10 shows the comparison of voltage profile of case 1 to case 5 of 69 bus network.

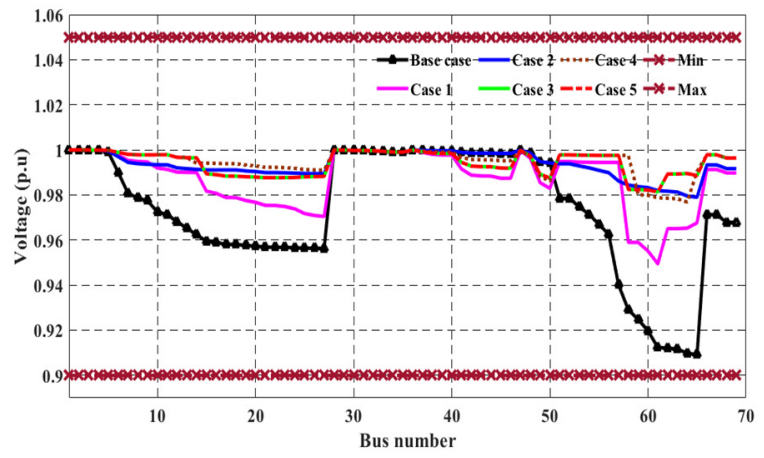

Fig. 10: Bus Voltage Profile of Case 1 to Case 5 for IEEE 69Bus System

Fig. 10 demonstrate that the voltage value is near to unity at all buses has been appeared in case 5 in which simultaneous OFR and DGs allocation. In addition, redistribution of current after the OFR and DG allocation in the branches are shown in Fig. 11. It is clear from Fig. 11 that, the current distribution is well uniform in all cases as compared to the base case, and it is within the desirable limit that is less than the maximum current. It is observed from Fig. 11, that current is more uniformly distributed in the branches of case 3 and case 5 compare to other cases. So as to show the superiority of $\mathrm{C}^{2} \mathrm{oDE}$ algorithm, the results of proposed $\mathrm{C}^{2} \mathrm{oDE}$ algorithm are compared with the most recent methods that are ACSA in [24], FWA in [25] and HSA in [5] and is presented in Table 6. Table 6 clearly shows that in the most of the cases in comparison to the objective function, proposed $\mathrm{C}^{2} \mathrm{oDE}$ algorithm is better than the ACSA [24], FWA [25] and HSA [5]. The convergence curve of IEEE 69-bus test system for all cases is shown in Fig. 12. Fig. 12 shows that, convergence curve of objective function is globally minimum in case 3 and case 5 compared to other cases.

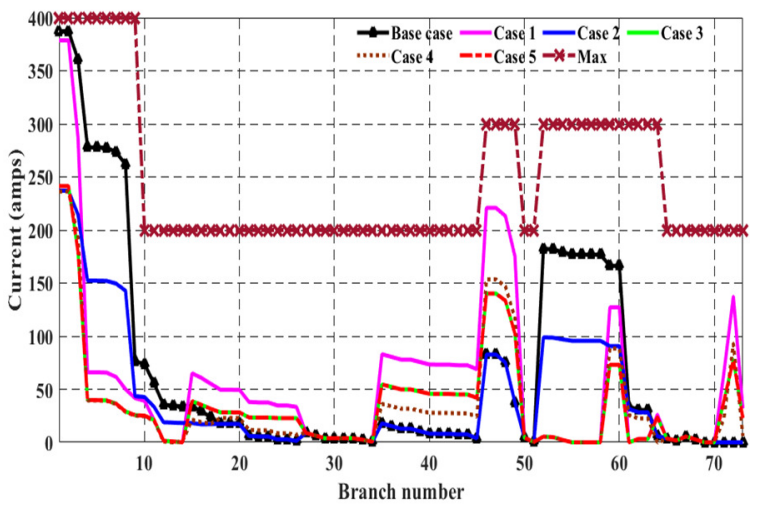

Fig. 11: Current Distribution in Branches of IEEE 69-Bus System

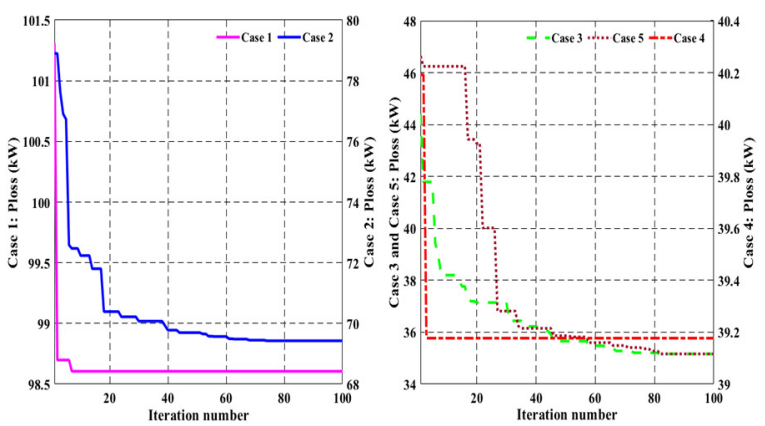

Fig. 12: Convergence Curve of Case 1 to Case 5 for IEEE 69-Bus

\section{IEEE 119-BUS SYSTEM}

In order to show the superiority of $\mathrm{C}^{2} \mathrm{oDE}, 119$-bus large-scale radial distribution system is considered under study, that consists of 132 branches, in which 117 branches are normally closed (connected with sectionalizing switches) and 15 normally open branches (connected with tie switches). The line and the load data is taken from [32]. In this system total complex power demand is $22.709 \mathrm{MW}+j 17.041$ MVAr. Typical single line diagram of 119-bus radial network is shown in Fig. 13, whereas, Table 7 shows the fundamental loops of this system. However, simulation results of all cases using proposed $\mathrm{C}^{2} \mathrm{oDE}$ algorithm are shown in Table 8.

It can be clearly shown in Table 8 that, initially power loss is $1298.1 \mathrm{~kW}$ that is decreased to 798.6484 , $667.2917,508.280,637.0014$ and 590.28 using case 1 , $2,3,4$, and 5 respectively. The percentage reduction of loss for case 1 to case 5 is $38.475,48.59,54.46$, 50.92 , and 54.52 respectively. Out of five cases, highest power loss reduction is appeared in case 3 


\section{Constrained Composite Differential Evolution Search for Optimal Site and Size of Distributed Generation Along with}

Reconfiguration in Radial Distribution Network

Table 8: Simulation Results of Case 1 to Case 5 for 119-Bus System

\begin{tabular}{|c|c|c|}
\hline Scenario & Item & Proposed $\mathrm{C}^{2} \mathrm{oDE}$ \\
\hline \multirow{3}{*}{ Base Case } & Tie switch branches & $118,119,120,121,122,123,124,125,126,127,128,129,130,131,132$ \\
\hline & $\mathrm{P}_{\text {Loss }}(\mathrm{kW})$ & 1298.1 \\
\hline & Min: bus voltage (p.u) & 0.8687 \\
\hline \multirow{4}{*}{$\begin{array}{l}\text { Case } 1 \\
\text { (reconfiguration } \\
\text { only) }\end{array}$} & Tie switch branches & $25,120,39,42,132,51,122,123,125,75,71,77,105,130,113$ \\
\hline & $\mathrm{P}_{\text {Loss }}(\mathrm{kW})$ & 798.6484 \\
\hline & $\%$ Loss reduction & 38.475 \\
\hline & Min: bus voltage (p.u) & 0.93211 \\
\hline \multirow{5}{*}{$\begin{array}{l}\text { Case2 (DG } \\
\text { allocation only) }\end{array}$} & Tie switch branches & $118,119,120,121,122,123,124,125,126,127,128,129,130,131,132$ \\
\hline & DG Size in MW (Bus Number) & 2.88327 (50), $2.97852(71), 3.11992(109)$ \\
\hline & $\mathrm{P}_{\text {Loss }}(\mathrm{kW})$ & 667.2917 \\
\hline & $\%$ Loss reduction & 48.59 \\
\hline & Min: bus voltage (p.u) & 0.954101 \\
\hline \multirow{5}{*}{$\begin{array}{l}\text { Case } 3 \text { (DG } \\
\text { allocation after } \\
\text { optimal } \\
\text { reconfiguration) }\end{array}$} & Tie switch branches & $25,120,39,42,132,51,122,123,125,75,71,77,105,130,113$ \\
\hline & DG Size in MW (Bus Number) & $2.41719(49), 1.43701(70), 2.13258(79)$ \\
\hline & $\mathrm{P}_{\text {Loss }}(\mathrm{kW})$ & 508.280 \\
\hline & $\%$ Loss reduction & 54.46 \\
\hline & Min: bus voltage (p.u) & 0.95203 \\
\hline \multirow{5}{*}{$\begin{array}{l}\text { Case } 4 \text { (optimal } \\
\text { reconfiguration after } \\
\text { DG installation) }\end{array}$} & Tie switch branches & $24,120,39,42,132,121,61,123,125,128,70,74,129,130,131$ \\
\hline & DG Size in MW (Bus Number) & $2.8832(50), 2.9785(71), 3.1199(109)$ \\
\hline & $\mathrm{P}_{\text {Loss }}(\mathrm{kW})$ & 637.0014 \\
\hline & $\%$ Loss reduction & 50.92 \\
\hline & Min: bus voltage (p.u) & 0.95366 \\
\hline \multirow{5}{*}{$\begin{array}{l}\text { Case } 5 \\
\text { (Simultaneous } \\
\text { optimal } \\
\text { reconfiguration and } \\
\text { DG installation) }\end{array}$} & Tie switch branches & $24,120,39,42,132,121,61,123,125,75,70,74,82,130,108$ \\
\hline & DG Size in MW (Bus Number) & $4.0430(91), 2.3135$ (110), $2.9077(50)$ \\
\hline & $\mathrm{P}_{\text {Loss }}(\mathrm{kW})$ & 590.28 \\
\hline & $\%$ Loss reduction & 54.52 \\
\hline & Min: bus voltage (p.u) & 0.95401 \\
\hline
\end{tabular}

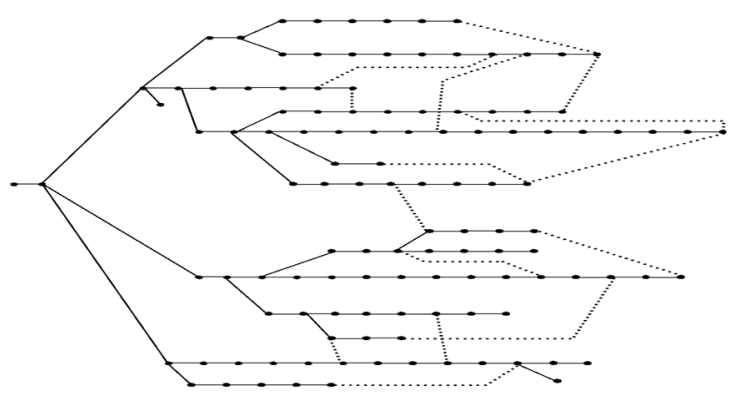

Fig 13: Online Diagram of IEEE 119 Bus

Table 7: Loops of 119 Bus Test System

\begin{tabular}{|c|c|}
\hline Loop & Branches \\
\hline $\mathrm{FL}_{1}$ & $\begin{array}{c}11,12,13,14,15,16,17,18,19,20,21,22,23,24, \\
\end{array}$ \\
\hline $\mathrm{FL}_{2}$ & $3,4,5,6,7,9,10,120$ \\
\hline $\mathrm{FL}_{3}$ & $8,27,28,37,38,39,124$ \\
\hline $\mathrm{FL}_{4}$ & $40,41,42,43,44,45,118$ \\
\hline $\mathrm{FL}_{5}$ & $29,30,31,32,33,34,132$ \\
\hline $\mathrm{FL}_{6}$ & $46,47,48,49,50,51,52,53,121$ \\
\hline $\mathrm{FL}_{7}$ & $54,55,56,57,58,59,60,61,122$ \\
\hline $\mathrm{FL}_{8}$ & $35,36,123$ \\
\hline $\mathrm{FL}_{9}$ & $1,62,63,64,88,89,90,95,125$ \\
\hline $\mathrm{FL}_{10}$ & $75,76,96,97,98,128$ \\
\hline $\mathrm{FL}_{11}$ & $65,66,67,68,69,70,71,72,126$ \\
\hline $\mathrm{FL}_{12}$ & $73,74,77,78,85,86,87,127$ \\
\hline $\mathrm{FL}_{13}$ & $79,80,81,82,105,106,107,129$ \\
\hline $\mathrm{FL}_{14}$ & $99,100,101,102,103,104,130$ \\
\hline $\mathrm{FL}_{15}$ & $108,109,113,114,115,116,117,131$ \\
\hline
\end{tabular}

using proposed $\mathrm{C}^{2} \mathrm{oDE}$ algorithm, that shows the superiority of the proposed algorithm. Furthermore, minimum voltage magnitude at a bus is upgraded from 0.8687 base case to $0.93211,0.954101,0.95203$, 0.95366 , and 0.95401 in case 1 to case 5 respectively. Furthermore, Table 9 shows the simulation results of case 1 (only reconfiguration), comparisons made with the existing latest methods.

The simulation results of optimal reconfiguration found by the proposed method $\mathrm{C}^{2} \mathrm{oDE}$ is improved than ASCA [24], ITS [32], MTS [11], CSA [10] and FWA [13] in comparison to active power loss. However, in comparison to voltage profile proposed algorithm is better than ASCA [24], CSA [10] and FWA [13], whereas approximately equal to the ITS [32] and CSA [10]. Fig. 14 shows the voltage enhancement for all the cases of 119-bus tests system.

It is clearly noticed from Fig. 14 that voltage level at all the buses has been enhanced after OFR and DG allocation, and operating voltage is within the minimum and maximum range. In addition, redistribution of current in the branches are well Mehran University Research Journal of Engineering and Technology, Vol. 39, No. 4, October 2020 [p-ISSN: 0254-7821, e-ISSN: 2413-7219] 
uniform in all cases as compared to the base case, and it is within the desirable limit that is less than the maximum current limit as shown in Fig. 15.

Table 9: Simulation Results in Comparison of Case 1 for 119-Bus

\begin{tabular}{|c|c|c|c|}
\hline Algorithms & Open Branches & $\begin{array}{c}P_{\text {Loss }} \\
(\mathrm{kW})\end{array}$ & $\begin{array}{l}\mathrm{V}_{\min } \\
\text { (p.u) }\end{array}$ \\
\hline Initial & $\begin{array}{l}119,120,121,122,123, \\
124,125,126,127,128, \\
129,130,131,132,133\end{array}$ & 1298.1 & 0.8678 \\
\hline Proposed & $\begin{array}{c}25,120,39,42,132,51 \\
122,123,125,75,71 \\
77,105,130,113\end{array}$ & 798.64 & 0.9321 \\
\hline ASCA [24] & $\begin{array}{c}42,25,23,121,50,58 \\
39,95,71,74,97,129 \\
130,109,34\end{array}$ & 855.04 & 0.9298 \\
\hline ITS [32] & $\begin{array}{c}42,26,23,51,122,58 \\
39,95,71,74,97,129, \\
130,109,34\end{array}$ & 867.4 & 0.9323 \\
\hline MTS [11] & $\begin{array}{c}42,26,23,51,122,58 \\
39,95,71,74,97,129 \\
130,109,34\end{array}$ & 867.4 & 0.9323 \\
\hline CSA [10] & $\begin{array}{c}42,25,23,121,50,58 \\
39,95,71,74,97,129 \\
130,109,34\end{array}$ & 855.04 & 0.9298 \\
\hline FWA [13] & $\begin{array}{c}42,25,23,121,50,58 \\
39,95,71,74,97,129 \\
130,109,34\end{array}$ & 855.04 & 0.9298 \\
\hline
\end{tabular}

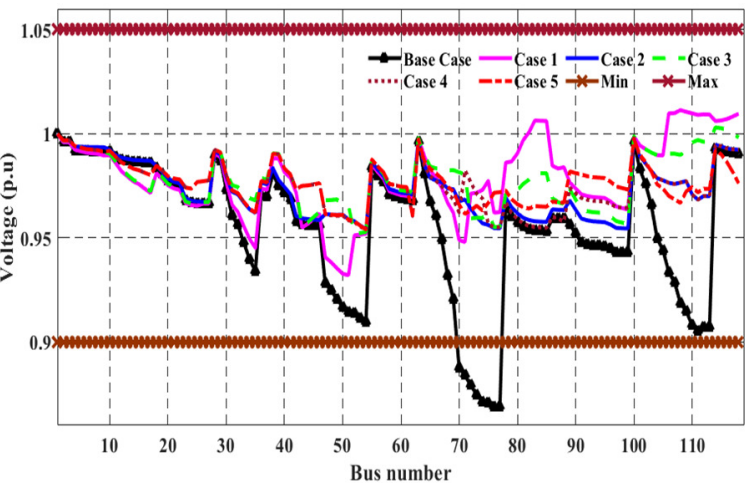

Fig. 14: Bus Voltage Profile of Case I to Case 5 for IEEE119 Bus System

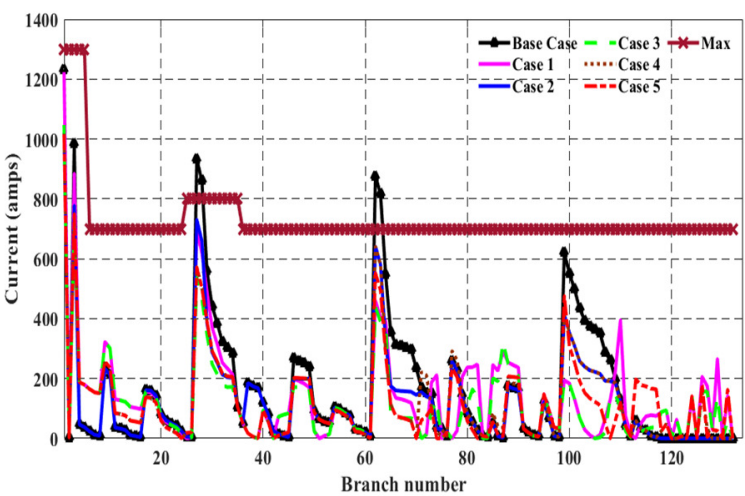

Fig. 15: Current Distribution in Branches of IEEE 119-Bus System
Fig. 15 clearly shows that the current is more uniformly distributed in all the branches of case 4 . It is observed from the Table 8, that in all cases the performance of proposed $\mathrm{C}^{2} \mathrm{ODE}$ algorithm is better especially in case 3 , in which decision variable is six, three for optimal site and three for optimal size. The convergence curves of IEEE 119-bus test system for case 1 to case 5 is shown in Fig. 16. It is noticed from Fig. 16 that the objective function (active power loss in $\mathrm{kW}$ ) is minimum in case 3 compared to all other cases.

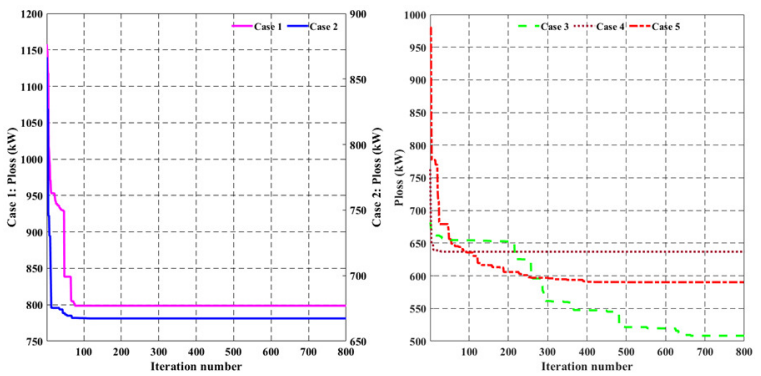

Fig. 16: Convergence Curve of Case 1 To Case 5 for IEEE 119-Bus System

\section{CONCLUSION}

In this paper, the new optimization technique $\left(\mathrm{C}^{2} \mathrm{oDE}\right)$ has been successfully applied for optimum feeder reconfiguration (OFR) and DG allocation problems. The objective is to minimize the active power loss considering standard IEEE 33-bus, 69-bus, and 119bus radial distribution networks. Furthermore, different study cases are simulated in order to show the applicability and effectiveness of the proposed algorithm. Simulated study cases include only OFR, only optimal DG allocation, OFR then DG allocation, DG allocation then OFR and simultaneous DG allocation and OFR are considered to minimize active power loss and improve in voltage profile. The proposed algorithm is incorporated with the most widely used constrained handling techniques such as feasibility rule and $\varepsilon$-constrained method in order to decrease the infeasible search space at the stage of trial vector generation and individual for the next generation. Simulation results demonstrate that case 5 is more effective in improving voltage and minimizing real power loss compared to all other cases. Moreover, the simulation results of proposed $\mathrm{C}^{2} \mathrm{ODE}$ algorithm are compared with the most recent methods. The 
output results have confirmed that the performance of $\mathrm{C}^{2} \mathrm{ODE}$ algorithm is better than ACSA, FWA, and HSA in most of the cases. Throughout this work only constant (PQ) load models are taken into account, however, in the future proposed work can be extended to include voltage sensitive loads such as constant current (I) constant impedance ( $\mathrm{Z}$ ) and mixed load models.

\section{ACKNOWLEDGMENT}

This research work is funded by the Quaid-e-Awam University of Engineering Science \& Technology Nawabshah, Sindh, Pakistan.

\section{REFERENCES}

[1] Ng, H. N., Salama M. M. A., Chikhani A. Y., "Classification of capacitor allocation techniques," IEEE Transactions on Power Delivery, vol. 15, no. 1, pp. 387-392, 2000.

[2] Kumar K., Jayabarathi T., "Power system reconfiguration and loss minimization for an distribution systems using bacterial foraging optimization algorithm," International Journal of Electrical Power \& Energy Systems, vol. 36, no. 1, pp. 13-17, 2012.

[3] Naik G.S., Khatod, D. K., Sharma, M. P., "Optimal allocation of combined DG and capacitor for real power loss minimization in distribution networks," International Journal of Electrical Power and Energy Systems, Vol. 53, pp. 967-973, 2013.

[4] Nguyen T. T., Truong A. V., "Distribution network reconfiguration for power loss minimization and voltage profile improvement using cuckoo search algorithm", International Journal of Electrical Power and Energy Systems, Vol. 68, pp. 233-242, 2015.

[5] Rao R., Ravindra K., Satish K., Narasimham S., "Power loss minimization in distribution system using network reconfiguration in the presence of distributed generation", IEEE Transactions on Power Systems, vol. 28, no. 1, pp. 317-325, 2013.

[6] Merlin A., Back H., "Search for a MinimalLoss Operating Spanning Tree Configuration in an Urban Power Distribution System," Proceedings of the 5th Power System Computation Conference (PSCC), 1975.

[7] Shirmohammadi, D. and Hong, H. W., "Reconfiguration of electric distribution networks for resistive line losses reduction",
IEEE Transactions on Power Delivery, Vol. 4, No. 2, pp. 1492-1498, 1989.

[8] Civanlar S., Grainger J. J., Yin H., Lee S. S. H., "Distribution feeder reconfiguration for loss reduction," IEEE Transactions on Power Delivery, Vol. 3, No. 3, pp. 1217-1223, 1988.

[9] Nara K., Shiose A., Kitagawa M., Ishihara T., "Implementation of genetic algorithm for distribution systems loss minimum reconfiguration". IEEE Transactions on Power Systems, Vol. 7, No. 3, pp. 1044-1051, 1992.

[10] Nguyen T., Truong V., "Distribution network reconfiguration for power loss minimization and voltage profile improvement using cuckoo search algorithm," International Journal of Electrical Power and Energy Systems, Vol. 68, pp. 233-242, 2015.

[11] Abdelaziz A. Y., Mohamed F. M., Mekhamer S. F., Badr M. A. L., "Distribution system reconfiguration using a modified Tabu Search algorithm", Electric Power Systems Research, Vol. 80, No. 8, pp. 943-953, 2010.

[12] Teimourzadeh S., Zare K., "Application of binary group search optimization to distribution network reconfiguration," International Journal of Electrical Power and Energy Systems, Vol. 62, pp. 461-468, 2014.

[13] Imran M.A., Kowsalya M., "A new power system reconfiguration scheme for power loss minimization and voltage profile enhancement using Fireworks Algorithm", International Journal of Electrical Power and Energy Systems, Vol. 62, pp. 312-322, 2014.

[14] Rao R. S., Narasimham S. V. L., Raju M. R., Rao A. S., "Optimal Network Reconfiguration of Large-Scale Distribution System Using Harmony Search Algorithm", IEEE Transactions on Power Systems, Vol. 26, No. 3, pp. 1080-1088, 2011.

[15] Duan, D.-L., Ling, X.-D., Wu, X.-Y., and Zhong, B., "Reconfiguration of distribution network for loss reduction and reliability improvement based on an enhanced genetic algorithm", International Journal of Electrical Power and Energy Systems, Vol. 64, pp. 88-95, 2015.

[16] Hung D. Q., Mithulananthan N., and Bansal, R. C., "An optimal investment planning framework for multiple distributed generation units in industrial distribution systems", Applied Energy, Vol. 124, pp. 62$72,2014$. 
[17] Doagou-Mojarrad H., Gharehpetian G. B., Rastegar H., and Olamaei J., "Optimal placement and sizing of DG (distributed generation) units in distribution networks by novel hybrid evolutionary algorithm", Energy, Vol. 54, pp. 129-138, 2013.

[18] Celli G., Ghiani E., Mocci S., Pilo F., "A multiobjective evolutionary algorithm for the sizing and siting of distributed generation", IEEE Transactions on Power Systems, Vol. 20, No. 2, pp. 750-757, 2005.

[19] Ayodele, T. R., Ogunjuyigbe A. S. O., Akinola. O. O., "Optimal Location, Sizing, and Appropriate Technology Selection of Distributed Generators for Minimizing Power Loss Using Genetic Algorithm," Journal of Renewable Energy, Vol. 2015, pp. 1-10, 2015.

[20] Mughees M., Goharawan F., Mughees A., "Volt/VAr Optimization of Distribution System with Integrated Distributed Generation," Mehran University Research Journal of Engineering and Technology, Vol. 36, No. 1, pp. 117-128, Jan 2017.

[21] Imran M.A., Kowsalya M., "Optimal size and siting of multiple distributed generators in distribution system using bacterial foraging optimization", Swarm and Evolutionary Computation, Vol. 15, pp. 58-65, 2014.

[22] Ugranlı F., Karatepe E., "Multipledistributed generation planning under load uncertainty and different penetration levels", International Journal of Electrical Power and Energy Systems, Vol. 46, pp. 132-144, 2013.

[23] Kayal P., Chanda C. K., "Placement of wind and solar based DGs in distribution system for power loss minimization and voltage stability improvement", International Journal of Electrical Power and Energy Systems, Vol. 53, pp. 795-809, 2013.

[24] NguyenT. T., Truong A. V., Phung T. A., "A novel method based on adaptive cuckoo search for optimal network reconfiguration and distributed generation allocation in distribution network," International Journal of Electrical Power and Energy Systems, Vol. 78, pp. 801-815, 2016.

[25] Imran M.A., Kowsalya M., Kothari D. P., "A novel integration technique for optimal network reconfiguration and distributed generation placement in power distribution networks", International Journal of Electrical Power and Energy Systems, Vol. 63, pp. 461-472, 2014.
[26] Wang B., Li H., Li J., Wang Y., "Composite Differential Evolution for Constrained Evolutionary Optimization", IEEE Transactions on Systems, Man, and Cybernetics: Systems, pp. 1-14, 2018.

[27] Jen-Hao T., "A direct approach for distribution system load flow solutions," IEEE Transactions on Power Delivery, Vol. 18, No. 3, pp. 882-887, 2003.

[28] Deb, K., "An efficient constraint handling method for genetic algorithms", Computer Methods in Applied Mechanics and Engineering, Vol. 186, No. 2, pp. 311-338, 2000.

[29] Takahama T., Sakai, S., "Efficient Constrained Optimization by the $\varepsilon$ Constrained Rank-Based Differential Evolution", Proceedings of the IEEE International Congress on Evolutionary Computation, 2012, pp. 1-8.

[30] Wolpert D. H., Macready W. G., "No free lunch theorems for optimization," IEEE Transactions on Evolutionary Computation, Vol. 1, No. 1, pp. 67-82, 1997.

[31] Zimmerman R. D., Murillo-Sanchez C. E., Thomas R. J., "MATPOWER: Steady-State Operations, Planning, and Analysis Tools for Power Systems Research and Education," IEEE Transactions on Power Systems, Vol. 26, No. 1, pp. 12-19, 2011.

[32] Zhang D., Fu Z., Zhang L., "An improved TS algorithm for loss-minimum reconfiguration in large-scale distribution systems", Electric Power Systems Research, Vol. 77, No. 5, pp. 685-694, 2007. 